DOI: $10.15593 / 2224-9354 / 2020.2 .10$

УДК 316.334 .56

\author{
E.H. Заборова
}

\title{
БУДУЩЕЕ ГОРОДОВ
}

\section{В ИНФОРМАЦИОННО-ЦИФРОВУЮ ЭПОХУ}

\begin{abstract}
В науке предвидение будущего возможно как прогнозирование, предполагающее экстраполяцию выявленных в ходе научных исследований тенденций на перспективу. Урбанизационные процессы в нашей стране протекают неоднозначно, в функционировании современных российских городов наблюдаются две ярко выраженные тенденции в зависимости от людности городских поселений. Малые города сокращаются и исчезают, при этом темпы сокращения таковы, что на повестке стоит вопрос об исчезновении малых городов. Большие и крупные - превращаются в агломерации, разрастаются и включают в сферу своего влияния близлежащие поселения. При этом все многочисленные проблемы больших и крупных городов сохраняются, так как агломерация в основном затрагивает межпоселенческие аспекты развития территорий. Выявленные тенденции функционирования малых и крупных городов развиваются в рамках стремительных современных научно-технологических процессов: информационной эпохи и цифровизации общественной жизни. В статье проведен анализ процессов, происходящих в производстве, банковском деле, торговле, образовании, культуре и других сферах городов под влиянием информационно-цифровых технологий. В результате анализ с неизбежностью подводит нас к выводу: сегодня для выполнения своих функций городам не требуется концентрация населения в одной пространственной точке. Выполнение классических экономической, торговой, образовательной, культурной и других функций все более приобретает виртуальный характер, их можно осуществлять дистанционно. Большие и крупные города уйдут с исторической арены, выполнив свою миссию. Малые и средние города получат мощный импульс для реновации. зирование.

Ключевые слова: информационная эпоха, цифровизация, малые и крупные города, прогно-
\end{abstract}

Введение. В настоящее время в городах на нашей планете проживает чуть более 50 \% населения земного шара и до самого последнего времени урбанизационные процессы не прекращали своего динамичного поступательного развития. Будут ли в будущем все жители Земли жить в городах? Если да, то в каких городах? Справится ли крупный город со своими многочисленными проблемами (транспортными, экологическими, жилищными, социальнопсихологическими) или ему суждено уйти с арены, выполнив свою историческую миссию? Эти и аналогичные вопросы давно волнуют как отечественных, так и зарубежных ученых.

На протяжении всей истории урбанистики наблюдается борьба двух социальных групп: тех, кто выступал «за» город, и тех, кто «против». Особенно ярко эта борьба проявилась в нашей стране в первые годы советской власти,

(C) Заборова Е.Н., 2020

Заборова Елена Николаевна - д-р социол. наук, профессор, завкафедрой прикладной социологии ФГБОУ ВО «Уральский государственный экономический университет», e-mail: ezaborova@yandex.ru. 
когда развернулась бурная дискуссия между «урбанистами» и «дезурбанистами». Сторонники первой концепции (А. Зеленко, Л. Сабсович) отвергали город капиталистического типа, представители второй - город как таковой (М. Гинзбург, М. Охитович) [1]. Будущий город мыслился как город-коммуна (И.И. Леонидов) [2] или же, напротив, как «зеленый город», размещенный вдоль транспортных потоков и представляющий собой малоэтажные жилые ячейки.

В рамках урбанистической версии развития города мы наблюдаем целую россыпь попыток справиться с решением проблемы совмещения идеологического идеала (идеи коллективизма и коммунизма), реальных потребностей личности и архитектурно-планировочного устройства городов. Это и концепция ступенчатой системы обслуживания (Г. Градов), концепция нового элемента расселения (А. Бабуров, А. Гутнов и др.), равномерного расселения (М. Бархин), кинетического расселения (А. Иконников), жесткого зонирования территории городов по функциям (жилье - работа - отдых) (Ле Корбюзье) [3], идея единого города для всего человечества - экуменополиса (К. Доксиадис, А. Тойнби), идеи акваполиса, экополиса и технополиса.

Предпринимались и попытки совмещения двух противоположных тенденций. Широкую известность получили идеи Э. Говарда, который предлагал создавать новые города, возможно более полно сочетающие преимущества городской и сельской жизни, что в конечном итоге означало уничтожение больших городов [4].

В данной работе мы попытаемся совместить анализ современных глобальных информационно-цифровых процессов и традиционные функции городов, акцентируя внимание на наиболее ярко выраженные тренды в развитии городских поселений.

Объект и методы исследования. Объектом исследования являются современные тенденции развития малых и крупных городов нашей страны в условиях информационно-цифровой эпохи.

В методологическом плане мы опираемся на концептуальные идеи и методологию социального прогнозирования, высказанные в трудах таких ученых, как А.С. Ахиезер, И.В. Бестужев-Лада, Н.В. Бордунов, В.Н. Стегний, P.В. Леньков и др. Прогнозирование будущего опирается на способность высшей нервной системы человека к опережающему отражению действительности. Социальное прогнозирование - достаточно сложный и трудоемкий процесс, типовая методика социального прогнозирования в ее наиболее развернутом виде представляет собой 44 исследовательские операции [5]. Социологическая наука использует такие методы, как экстраполяция, экспертная оценка, моделирование, аналогии, составление сценариев [6]. В экономических науках активно используются математические методы моделирования социально-экономических процессов $[7,8]$.

В данной работе мы используем метод экстраполяции. Прогноз строится на фактах, на анализе данных, на экстраполяции существующих тенденций. 
При этом прогноз всегда вариативен, это не 100 \% предвидение, но сценарии развития. Задача - «представить варианты будущего, „спроектировать“ его и понять, какой человек может в этом будущем жить» [9].

Эмпирической базой работы послужили данные общей государственной и региональной статистики, собственные вычисления автора по динамике развития малых и больших городов региона Свердловская область, вторичный анализ статистики по наукоградам. В работе также использованы материалы социологических исследований зарубежных и отечественных авторов по проблемам влияния информационно-цифровых процессов на функционирование и развитие городов.

Результаты и обсуждение. Какие тренды мы наблюдаем в развитии городов нашей страны сегодня? Для ответа на этот вопрос следует прежде всего отметить, что есть разные тенденции у городов разной людности. Есть города малые и средние и есть города крупные и большие. Расхождение в трендах можно наглядно продемонстрировать на примере Свердловской области, где половина жителей проживает в малых и средних городах, а другая половина в мегаполисе Екатеринбурге.

Свердловская область считается одним из самых высокоурбанизированных регионов, так как по численности городов (47) она опережает многие другие регионы, уступая только Ленинградской и Московской областям. В ней представлены все типы поселений, от малых до крупнейших. Основная доля городов - это малые города с численностью жителей менее 50 тыс. чел. (35 городов). Один город принадлежит к категории «крупнейший», это г. Екатеринбург с населением 1483119 чел. (2019 г.). Как показывают данные статистики, у малых и больших городов разный вектор развития. Численность населения малых и средних городов сокращается, при этом темпы сокращения нарастают: если в 2017 г. таких городов было 15, то в 2019 г. - 27. И это тенденция совпадает с общероссийской. В подавляющем большинстве малых городов РФ происходит сокращение населения в целом примерно на 3 \% в год (по некоторым городам до 11 \% в год), что приводит к угрозе их исчезновения [10].

Другая тенденция наблюдается у крупных и больших городов. Они преобразуются в агломерации. Агломерацию принято считать этапом в развитии современных урбанизационных процессов. В настоящее время на планете, по некоторым данным, насчитывается более 2600 агломераций, в том числе в нашей стране разные авторы называют на сегодняшний день от 50 до 100 городских агломераций [11]. Следует заметить, что формирование агломерации не снимает все те многочисленные проблемы, которыми «богат» каждый крупный город.

Город - противоречивое явление, для него характерна разноплановость происходящих в нем процессов. Так, с одной стороны, несомненным преимуществом крупного города можно считать развитую транспортную инфраструк- 
туру, с другой - она же порождает серьезную экологическую проблему (главный источник загрязнения городского воздуха - автомобили) и транспортные проблемы (проблемы пробок на дорогах, парковок). Город предлагает человеку море информации, россыпь развлечений. В результате возникают дифференциация социокультурных групп, различия ценностно-смысловых ориентиров, одиночество в толпе, девиантные формы поведения [12, с. 35]. К сказанному можно добавить жилищную проблему, проблему потенциальной угрозы распространения эпидемий в силу скученности населения и многие другие.

Что же ожидает малые и крупные города в будущем? И вот здесь мы со всей внимательностью должны посмотреть, в какую эпоху мы живем и куда идут современные исторические процессы. Как хорошо известно, мы живем в информационно-цифровую эпоху, и эта тенденция проявляет себя все ярче во всех сферах жизни общества. Возникает исследовательский вопрос: как модифицируются функции крупных городов в настоящее время под влиянием информационно-цифровых процессов? Мы не ставим перед собой задачу рассмотреть все функции городов и провести полный список доказательств по каждой функции. Остановимся только на наиболее приоритетных функциях и их модификациях в современную эпоху.

Важнейшей функцией городов считается экономическая функция. Города важны для поступательного развития человечества, так как в них сконцентрированы основные промышленные предприятия, квалифицированная рабочая силы. Однако сегодня в России появилась новая тенденция - формируется цифровая экономика. Цифровую экономику определяют такие основные технологии, как облачная технология, распределенных вычислений, технология больших данных, интернет-вещей, цифровая платформа. Эти сервисы способны выполнять планирование, анализ, а также предоставлять связь непосредственно с рынком (клиентами, производителями и т.д.).

Что является следствием этих процессов? Можно перечислить ряд результатов, важных для нашей темы: робототехника и новые информационные технологии (ИТ) сокращают долю неквалифицированного труда; нарастает потребность в труде квалифицированном; возрастает число тех, кто может работать дистанционно, удаленно. Исследования показывают, что в 2020 г. 20 \% рабочих мест в России будут виртуальными [13]. К удаленной работе в сфере ИТ готовы $67 \%$ специалистов.

Финансовая функция. Города - это финансовые центры. Однако сегодня подавляющее число банковских операций можно произвести, не выходя из дома. Банки превращаются в ИТ-компании с банковской лицензией. Уже сейчас посредством любого технического устройства (компьютера, планшета, мобильного телефона и т.д.) можно удовлетворять все возникающие потребности клиентов банков быстро, эффективно и в круглосуточном режиме. Банк будущего - это интернет-банк и мобильный банкинг. 
Торговая функция. Города - центры торговли. Сегодня огромную популярность получила интернет-торговля. Посредством интернет-магазинов можно заказать практически любой товар, в том числе из-за рубежа. В 2018 г. рынок интернет-торговли увеличился почти на $60 \%$, показав лучший прирост почти за 10 лет [13]. Исследования показывают, что по сравнению с прошлым годом доля россиян, делающих покупки в интернете, выросла, теперь она составляет $42 \%$ - в два раза больше, чем в 2015 г. [14].

Образовательная функияия. Города - центры образования и науки. Сегодня все большое распространение получает онлайн-образование. Данные научных исследований свидетельствуют: хотя доля дистанционного обучения на внутреннем рынке бизнес-образования России составляет 1,1\% (для сравнения - в США, Японии и некоторых европейских стран 20-30\%.), но важно отметить, что темпы роста российского рынка в настоящий момент опережают динамику мирового рынка [15]. Следует учитывать два факта: онлайнобразование - непреодолимый тренд современности, и есть две могучие силы, которые заинтересованы в таком образовании - сами учащиеся и руководители вузов [16].

Культурная функция. Города - центры концентрации культурного наследия человечества, здесь расположены библиотеки, музеи, кинотеатры, спортивные сооружения. Однако сегодня, благодаря техническим средствам, люди могут приобщиться ко всем этим благам через экранную культуру: практически все есть в интернете.

Город всегда характеризовался наличием огромного числа людей и формализованностью контактов между ними. Сегодня этот процесс стал еще глубже. Информационно-цифровые процессы вырывают личность из паутины семейных и общинных связей, делая его атомарным, индивидуальным, одиноким. Семья как главная ячейка общества переживает глубокий кризис: общество перешло к индивидуальному, самостоятельному поиску партнера без учета мнения членов семьи; взрослые дети и родители предпочитают жить раздельно; соседские общности не существуют или стали редким явлением в многоквартирных городских домах. Отсутствие реальных связей заменяется связями виртуальными: 82 \% россиян зарегистрированы в социальных сетях. Люди знакомятся, общаются, развлекаются виртуально. Для такого поведения нет никакой нужды находиться в многолюдном, шумном, загазованном и полном проблем городе, так можно жить и удаленно от больших городов.

Это далеко неполный перечень модификаций функций городов, однако уже из него можно сделать вывод: при нарастании этих и многих других информационно-цифровых тенденций у людей исчезнет необходимость скученного проживания в крупных городах. Для выполнения своих важнейших функций городу все меньше необходимо пространственное объединение людей на одной территории, в рамках городской среды. Крупные и большие го- 
рода постепенно уйдут с исторической арены, выполнив свою важную миссию.

В прошлом люди, обладающие достатком, всегда стремились покинуть крупный город, особенно в летние месяцы. Современные технологии позволяют людям строить комфортабельные отдельно стоящие дома и при этом иметь все те блага, которые предлагает крупный город. Сегодня у людей появляется возможность покинуть крупный город и круглогодично жить в малом или среднем городе, нивелирующем классические недостатки крупного города и его проблемы. У малых и средних городов появляется прекрасный исторический шанс снова развиться, реанимироваться.

Т.А. Верещагина, П.Я. Дегтярев, А.И. Тюнин выделили четыре сценария стратегического развития малых городов Челябинской области: малые города центры развития перерабатывающих отраслей, сферы обслуживания; центры туризма и рекреации; центры размещения цехов и филиалов головных предприятий больших городов; центры науки и высоких технологий [17, с. 58]. Предложенная авторами схема, на наш взгляд, применима и к другим регионам страны. Но, как представляется, ее необходимо дополнить еще одним, пятым вариантом: малые города как элементы агломерации.

Особо следует обратить внимание на потенциал малых городов с точки зрения неоиндустриализации и цифровой экономики [18, с. 37]. В настоящий момент, согласно федеральному закону, в стране насчитывается 13 наукоградов (технополисов). Наши расчеты показали, что 4 из них принадлежат к группе малых городов, 5 - к средним и только 4 - к большим.

Существует и более расширенный список, в который наряду с наукоградами включены другие пространственные точки локализации инновационных производств, центры научных поисков, развития цифровых технологий, ЗАТО, территории, связанные с оборонной промышленностью и пр. В настоящий момент насчитывает более 70 таких точек локализации [19] и их распределение, по нашим подсчетам, выглядит следующим образом: 36,6 \% - малые города и районы городов; 26,8 \% - средние города; $15,5 \%$ - большие; 2,8 \% - крупные; 18,3 \% - сельские поселения.

Наиболее слабым местом в современном переходе от проживания в крупных и больших городах к городам малым является транспортная проблема: люди давно переехали бы в пригороды, будь у них быстрый и доступный индивидуальный транспорт. Но уже сегодня ведутся активные разработки летающего мотоцикла - ховербайка (hoverbike) и летающей доски - ховерборда (hoverboard) [20]. Как только такие летательные средства станут широко распространенными и будет создана соответствующая инфраструктура, то процесс перетекания населения из больших городов в малые резко ускорится.

Несомненно, выявленные тенденции не будут реализовываться автоматически и без проблем. Всегда обнаружатся какие-то трудности. Однако, как нам представляется, технический и научный прогресс не остановить. 
Bbыводы. В настоящую эпоху, неслучайно названную информационной, не только изменяется роль и значение информации, но нарастающими темпами в жизнь общества внедряются современные цифровые технологии. Проникая во все сферы жизни общества, информационные технологии видоизменяют функции города, в частности они уже не требуют для их реализации большой концентрации людей в одной пространственной точке, многие виды работ уже можно осуществлять дистанционно. Тем самым подрывается сама основа крупных городов как центров расселения, центров промышленности, банковского дела, образования, науки, логистических центров.

Современная эпоха создает условия для реализации идеи Ф. Энгельса, который говорил: «...в лице крупных городов цивилизация оставила нам такое наследие, избавиться от которого будет стоить много времени и усилий. Но они должны быть устранены - и будут устранены, хотя бы это был очень продолжительный процесс» [21].

\section{Список литературы}

1. Анимица Е.Г., Власова Н.Ю. Градоведение. - Екатеринбург: Изд-во УрГЭУ, 2008. - 417 с.

2. Леонидов И.И. Проект социалистического расселения при Магнитогорском химико-металлургическом комбинате // Современная архитектура. 1930. - № 3. - С. 1-25.

3. Ле Корбюзье. Три формы расселения. Афинская хартия / пер. с фр. Ж. Розенбаума. - М.: Стройиздат, 1976. - 136 с.

4. Говард Э. Города будущего. - СПб.: Тип. Т-ва Общественная польза. 1911. - 197 c.

5. Бестужев-Лада И.В. Алгоритм прогнозного обоснования социального нововведения [Электронный ресурс]. - URL: https://docviewer.yandex.ru/view/ (дата обращения: 03.02.2020).

6. Стегний В.Н. Социальное прогнозирование и проектирование: учеб. для акад. бакалавриата. - М.: Юрайт, 2018. - 182 с.

7. Бочарова Т.А. Моделирование как средство социального прогнозирования // Дискурс. - 2019. - № 3(29). - С. 88-93.

8. Леньков Р.В. Социальное прогнозирование и проектирование / ЦСП и М. - М., 2013. - 192 с.

9. Капица С.П., Курдюмов С.П., Малинецкий Г.Г. Синергетика и прогнозы будущего. - 3-е изд. - М.: Едиториал УРСС, 2003. - 288 с.

10. Социально-экономическое развитие малых городов Российской Федерации на период 2015-2020 годов [Электронный ресурс]: Концепция Федеральной целевой программы. - URL: https://mert.tatarstan.ru/file/\%... (дата обращения: 20.12.2019). 
11. Елшина А.А. Городские агломерации: теоретические проблемы и анализ зарубежного опыта // Современные научные исследования и инновации: электрон. науч.-практ. журн. - URL: http://web.snauka.ru/issues/2015/07/56419] (дата обращения: 13.11. 2019).

12. Заборова Е.Н. Городское управление: учеб. пособие. - Екатеринбург: Изд-во Урал. ун-та, 2014. - 296 с.

13. Пятая часть россиян будет работать удаленно к 2020 году [Электронный ресурс]. - URL: https://www.rbc.ru/technology_and_media/17/06/2015/55805 15f9a7947e7bf4bfc99 (дата обращения: 3.02.2020).

14. Развитие онлайн-торговли в России [Электронный ресурс]. - URL: https://yandex.ru/company/researches/2019/market-gfk] (дата обращения: 4.02.20202).

15. Анализ российского рынка дистанционного обучения: итоги 2018 г., прогноз до 2021 г. [Электронный pecypc]. - URL: https://marketing. rbc.ru/articles/10886/ (дата обращения: 5.02.2020).

16. Заборова Е.Н., Глазкова И.Г., Маркова Т.Л. Дистанционное обучение: мнение студентов // Социологические исследования. - 2017. - № 2. - С. 131-139.

17. Верещагина Т.А., Дегтярев П.Я., Тюнин А.И. Кризис традиционной модели развития малых городов // Вестник Челябинского государственного университета. Экономические науки. - 2018. - Вып. 60, № 3 (413). - С. 53-60.

18. Столицы и регионы в современной России: мифы и реальность пятнадцать лет спустя. - М.: Весь мир, 2018. - 312 с.

19. Обзор крупнейших наукоградов России [Электронный ресурс]. - URL: https:/viafuture.ru/privlechenie-investitsij/naukogrady-rossii (дата обращения: 10.02.2019).

20. Реактивный мотоцикл и летающая доска: спецтранспорт для спецназа [Электронный ресурс]. - URL: http://yandex.ru/clck/jsredir?bu=1yf55j\&from= yandex.ru\% (дата обращения: 6.02.2020).

21. Энгельс Ф. Анти-Дюринг // Маркс К., Энгельс Ф. Соч. - 2-е изд. T. $20 .-827$ c.

\section{References}

1. Animitsa E.G., Vlasova N.Iu. Gradovedenie [City studies]. Yekaterinburg, Ural State University of Economics, 2008, 417 p.

2. Leonidov I.I. Proekt sotsialisticheskogo rasseleniia pri Magnitogorskom khimiko-metallurgicheskom kombinate [The project of socialist settlement at Magnitogorsk iron and steel works]. Sovremennaia arkhitektura, 1930, no. 3, pp. 1-25.

3. Le Corbusier. La Charte d'Athènes (Russ. ed.: Le Korbiuz'e. Tri formy rasseleniia. Afinskaia khartiia. Moscow, Stroiizdat, 1976, 136 p.).

4. Howard E. Garden cities of To-morrow (Russ. ed.: Govard E. Goroda budushchego. St. Petersburg, Obshchestvennaia pol'za, 1911, 197 p.). 
5. Bestuzhev-Lada I.V. Algoritm prognoznogo obosnovaniia sotsial'nogo novovvedeniia [Algorithm for predictive justification of social innovation]. Available at: https://docviewer.yandex.ru/view/ (accessed 03 February 2020).

6. Stegnii V.N. Sotsial'noe prognozirovanie i proektirovanie [Social forecasting and projecting]. Moscow, Iurait, 2018, $182 \mathrm{p}$.

7. Bocharova T.A. Modelirovanie kak sredstvo sotsial'nogo prognozirovaniia [Modeling as a means of social forecasting]. Diskurs, 2019, no. 3(29), pp. 88-93.

8. Len'kov R.V. Sotsial'noe prognozirovanie i proektirovanie [Social forecasting and projecting]. Moscow, Center of Social Forecasting and Marketing, 2013, 192 p.

9. Kapitsa S.P., Kurdiumov S.P., Malinetskii G.G. Sinergetika i prognozy budushchego [Synergetics and forecasts of the future]. 3rd ed., Moscow, Editorial URSS, 2003, $288 \mathrm{p}$.

10. Sotsial'no-ekonomicheskoe razvitie malykh gorodov Rossiiskoi Federatsii na period 2015-2020 godov [Socio-economic development of small cities of the Russian Federation for the period 2015-2020]. Kontseptsiia Federal'noi tselevoi programmy, available at: https://mert.tatarstan.ru/file/\%... (accessed 20 December 2019).

11. Elshina A.A. Gorodskie aglomeratsii: teoreticheskie problemy i analiz zarubezhnogo opyta [Urban agglomerations: Theoretical problems and the analysis of foreign experience]. Sovremennye nauchnye issledovaniia i innovatsii, available at: http://web.snauka.ru/issues/2015/07/56419 (accessed13 November 2019).

12. Zaborova E.N. Gorodskoe upravlenie [Urban governance]. Yekaterinburg, Ural University, 2014, 296 p.

13. Piataia chast' rossiian budet rabotat' udalenno k 2020 godu [One fifth of the Russians will work remotely by 2020]. Available at: https://www.rbc.ru/technology_and_media/17/06/2015/5580515f9a7947e7bf4bfc99 (accessed 03 February 2020).

14. Razvitie onlain-torgovli $\mathrm{v}$ Rossii [The development of online trading in Russia]. Available at: https://yandex.ru/company/researches/2019/market-gfk (accessed 04 February 2020).

15. Analiz rossiiskogo rynka distantsionnogo obucheniia: itogi 2018 g., prognoz do $2021 \mathrm{~g}$. [Analysis of the market of distance learning in Russia: Results of 2018, forecast until 2021]. Available at: //https://marketing.rbc.ru/articles/10886/ (accessed 05 February 2020).

16. Zaborova E.N., Glazkova I.G., Markova T.L. Distantsionnoe obuchenie: mnenie studentov [Distance learning: Students' opinion]. Sotsiologicheskie issledovaniia, 2017, no. 2, pp. 131-139.

17. Vereshchagina T.A., Degtiarev P.Ia., Tiunin A.I. Krizis traditsionnoi modeli razvitiia malykh gorodov [Crisis of the traditional model of development of small cities]. Vestnik Cheliabinskogo gosudarstvennogo universiteta. Ekonomicheskie nauki, 2018, iss. 60, no. 3(413), pp. 53-60. 
18. Stolitsy i regiony v sovremennoi Rossii: mify i real'nost' piatnadtsat' let spustia [The capitals and regions of modern Russia: Myths and facts fifteen years later]. Moscow, Ves' mir, 2018, 312 p.

19. Obzor krupneishikh naukogradov Rossii [Overview of the largest science cities in Russia]. Available at: https://viafuture.ru/privlechenie-investitsij/ naukogrady-rossii (accessed 10 February 2019).

20. Reaktivnyi mototsikl i letaiushchaia doska: spetstransport dlia spetsnaza [Jet motorcycle and flying board: Special vehicles for Special Forces]. Available at: http://yandex.ru/clck/jsredir?bu=1yf55j\&from=yandex.ru\% (accessed 06 February 2020).

21. Engels F. Anti-Dühring (Russ. ed.: Engel's F. Anti-Diuring. Marks K., Engel's F. Soch. 2nd ed., vol. 20, 827 p.).

Оригинальность $87 \%$

Получено 06.02.2020 Принято 10.03.2020 Опубликовано 29.06.2020

\title{
E.N. Zaborova
}

\section{THE FUTURE OF CITIES}

\section{IN THE INFORMATION AND DIGITAL AGE}

\begin{abstract}
In science, foreseeing the future means prediction that involves extrapolating trends identified in the course of scientific research into the future. Urbanization processes in Russia are ambiguous, there are two distinct trends in the functioning of modern Russian cities, depending on the population of urban settlements. Small towns are shrinking and disappearing, and the rate of decline is such that the issue of small towns disappearance is on the agenda. Large cities turn into agglomerations, grow and include nearby settlements in their sphere of influence. At the same time, all the numerous problems of large cities remain, since agglomeration mainly affects the inter-settlement aspects of territory development. The identified trends in the functioning of small and large cities are developing within the framework of rapid modern scientific and technological processes: the information age and the digitalization of public life. The article analyzes the processes occurring in manufacturing, banking, trade, education, culture and other areas of cities under the influence of information and digital technologies. As a result, the analysis inevitably leads us to the conclusion that today cities do not need to concentrate their population in a single spatial point to perform their functions. Classical economic, commercial, educational, cultural, and other functions are increasingly becoming virtual and can be performed remotely. Big and large cities will leave the historic arena after completing their mission. Small and medium-sized cities will receive a powerful impetus for renovation.

Keywords: information age, digitalization, small and large cities, forecasting.
\end{abstract}

Elena N. Zaborova - Doctor of Sociology, Professor, Head of the Department of Applied Sociology, Ural State University of Economics, e-mail: ezaborova@yandex.ru.

Received 06.02.2020 Accepted 10.03.2020 Published 29.06.2020 